\title{
Toxic anthropogenic pollutants reach the deepest ocean on Earth
}

\author{
S. Dasgupta ${ }^{1}$, X. Peng ${ }^{1 *}$, S. Chen ${ }^{1}$, J. Li $^{1}$, M. Du${ }^{1}$, \\ Y.-H. Zhou ${ }^{2}$, G. Zhong ${ }^{3}$, H. Xu' ${ }^{1}$, K. Ta ${ }^{1}$
}

Abstract

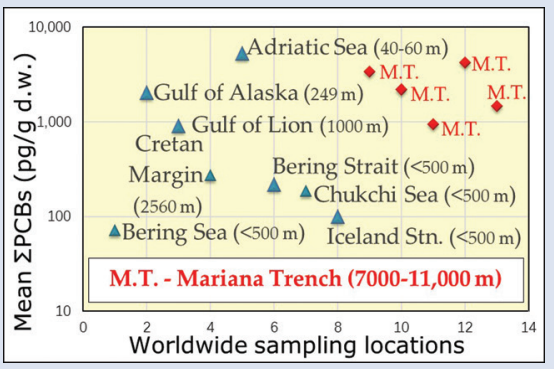

Persistent organic pollutants (PCBs and PBDEs) were analysed in sediment core samples $(0-2 \mathrm{~cm})$ from the southern Mariana Trench at water depths of 7000$11000 \mathrm{~m}$. ¿PCBs concentrations ranged from 931 to $4195 \mathrm{pg} / \mathrm{g}$, far higher than those recorded before in marine sediments from shallower depths. Toxic Equivalence (TEQ) of dl-PCBs ranged from $0.650-14.9 \mathrm{pg} / \mathrm{g}$, which is higher than most marine surficial sediments at $<500-2500 \mathrm{~m}$ ocean depth, recovered from semi-industrial to industrial areas. However, $\sum_{8}$ PBDEs values (averaging 136 $\mathrm{pg} / \mathrm{g}$ ) were lower than those in surficial sediments from shelf areas recorded in past studies. Evidently, anthropogenic pollutants have reached the deepest realm on Earth, and the Mariana Trench acts as a repository for POPs amplification. The high concentration of PCBs is an eye-opener, which is directly affecting our deep sea ecosystems, considering their pervasiveness and persistence in trench sediments.

Received 4 February 2018 | Accepted 18 April 2018 | Published 14 May 2018

\section{Letter}

The deep ocean arguably acts as the largest potential sink for discarded pollutants (Dachs et al., 2002). However, the hadal zone ( 6000 to $11000 \mathrm{~m}$ deep), which represents the deepest ocean on Earth, has largely been unexplored due to its remoteness. Of all the toxic anthropogenic pollutants damaging the oceans, persistent organic pollutants (POPs) are of particular concern due to their robust residence time in the environment (Kukučka et al., 2015), global transport through atmospheric and oceanic currents (Wania and Mackay, 1996), and their ability to bioaccumulate in marine foodwebs (Lohmann et al., 2007), resulting in organism endocrine disruption (Rhind, 2012) and other adverse health effects. Studies revealing presence of POPs in surface to deep marine sediments are plentiful (e.g., Iwata et al., 1994; Ma et al., 2015; Combi et al., 2016; Neira et al., 2018), but none of them probed beyond the continental shelf area, leaving the real "depth" of the oceans practically unexplored. In a latest study, Jamieson et al. (2017) reported high concentrations of POPs in endemic amphipod fauna from the Mariana and Kermadec Trenches. The signature of these pollutants through bioaccumulation could, however, be markedly different from that residing in the sediments.

The Mariana Trench is located in the western Pacific Ocean, where the Pacific Plate subducts beneath the Mariana and Philippine Sea Plates at convergence rates of $4-8 \mathrm{~cm} / \mathrm{yr}$.
The southern Mariana Trench encloses the deepest point on the Earth's surface-the Challenger Deep, which is $11034 \mathrm{~m}$ down, and $2 \mathrm{~km}$ deeper than the average depth along the axis of the Mariana Trench (Fujioka et al., 2002).

We detected polychlorinated biphenyls (PCBs) and polybrominated diphenyl ethers (PBDEs) in five sediment samples recovered from the southern Mariana Trench at ocean depths of 6980 m (C1-I-M-S015B02), 8638 m (C1-I-M-S078B10), 9373 m (TS03-S106GT02 (S) and TS03-S106GT02 (D) for top and bottom surface of the core respectively), and $10908 \mathrm{~m}$ (TS03S090LANDER11), (Fig. 1), during TS03 Hadal Trench Cruise carried out via R/V Tansuo Yihao on June, 2017 (See Table S-1 for sampling location details).

The prominent finding was that, 36 PCB and 10 PBDE congeners (Figs. 2 and 3 respectively) were detected. Lower-chlorinated congeners such as CB-8, CB-37, CB-52 and CB-60 were most abundant (refer to Table S-2), and their concentrations ranged from 1460 to $3300 \mathrm{pg} / \mathrm{g}$. For PBDEs, concentrations ranged from 245 (TS03-S106GT102 (S)) to $591 \mathrm{pg} / \mathrm{g}$ (TS03-S090LANDER11) (Table S-3). Low and medium weight PBDEs, such as BDE-47 and BDE-153 were more common in the samples. However, higher weight BDEs 207 and 208 were detected in C1-I-M-S015B02 and TS03S090LANDER11, with high concentrations of 266 and 280 $\mathrm{pg} / \mathrm{g}$ respectively.

\footnotetext{
1. Deep Sea Science Division, Institute of Deep Sea Science and Engineering, Chinese Academy of Sciences, Sanya, Hainan 572000, China

2. State Key Laboratory of Pollution Control and Resource Reuse, College of Environmental Science and Engineering, Tongii University, Shanghai 200092, China

3. State Key Laboratory of Organic Geochemistry, Guangzhou Institute of Geochemistry, Chinese Academy of Sciences, Guangzhou 510640, China

Corresponding author (email: xtpeng@idsse.ac.cn)
} 


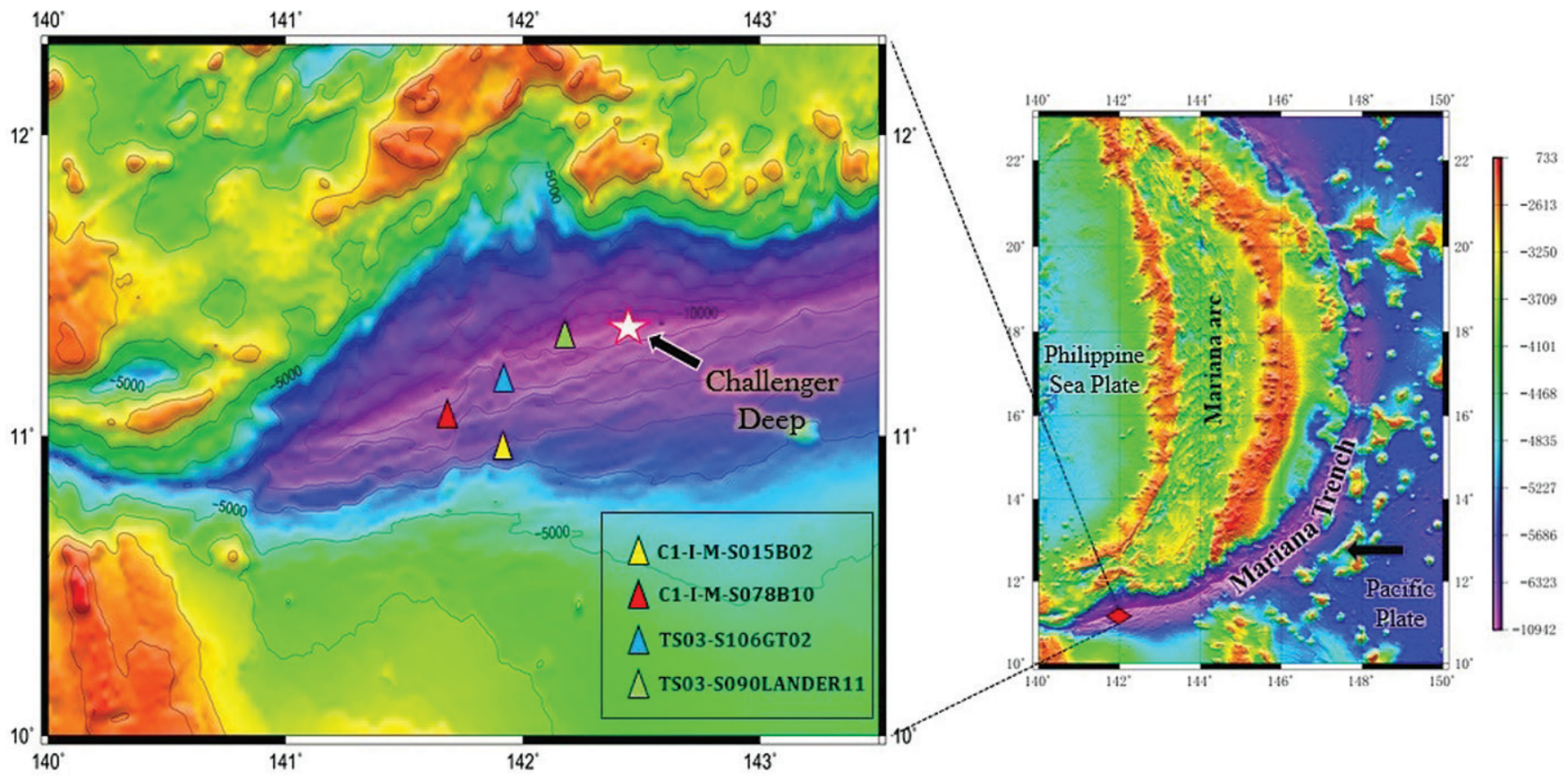

Figure 1 Sampling location map of Mariana Trench sediments.

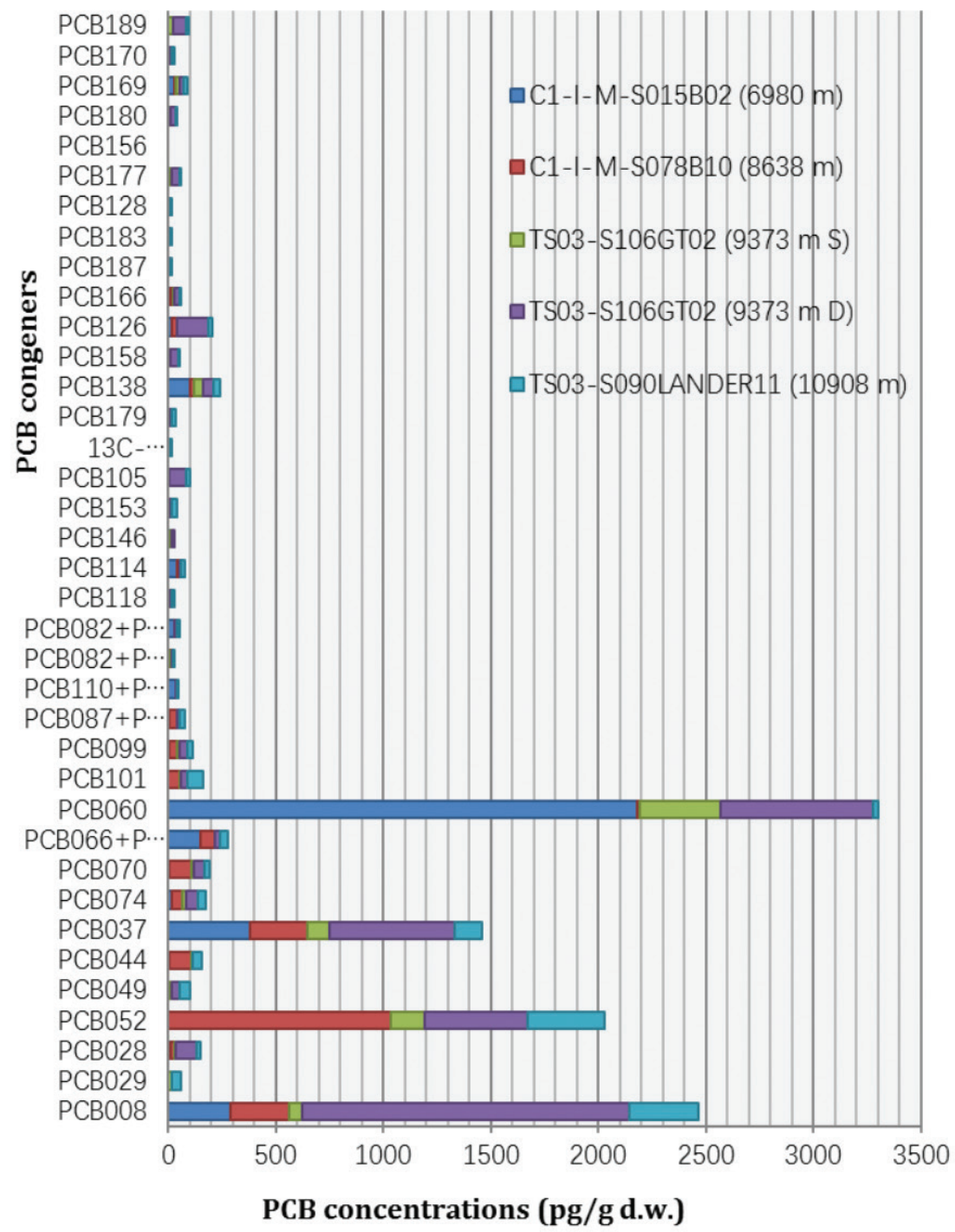

Figure 2 Concentrations of PCB congeners (pg/g d.w.) for different sampling locations at various water depths, as represented by coloured stacked bars. Refer to Table S-2 for details. 


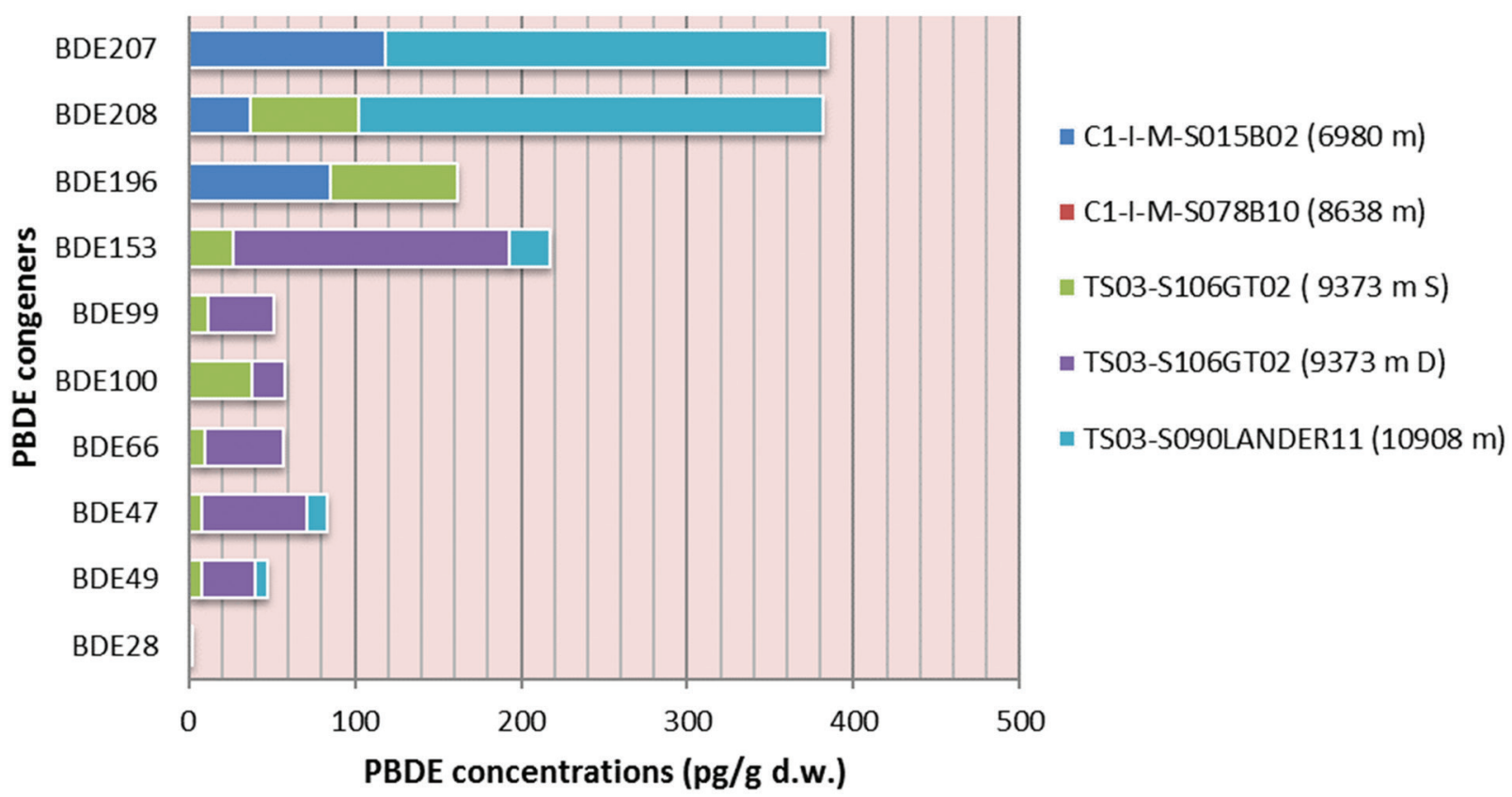

Figure 3 Concentrations of PBDE congeners ( $\mathrm{pg} / \mathrm{g} \mathrm{d}$ d.w.) for different sampling locations at various water depths, as represented by coloured stacked bars. Refer to Table S-3 for details.

$\sum P C B s(p g / g)$ concentrations ranged from 931-4195 pg/g dry weight in all five sediment samples. The Mariana sediments showed higher levels of low- and medium-chlorinated PCB congeners. It is noteworthy that no clear trend of $\Sigma \mathrm{PCB}$ variation with water depth was observed (Fig. S-1).

The seven "indicator PCBs" (Table S-4) chosen following the International Council for the Exploration of the Sea (ICES) convention contributed to $22 \%$ of all PCBs. They showed highest $\Sigma_{7}$ PCBs values at depths of $8638 \mathrm{~m}$ and $9373 \mathrm{~m}$. CB-52 was abundant in most of the samples, except in C1-I-MS015B02, where it was not detected. These PCBs are indicative of lipophilic contaminants, but their concentrations can vary with the contaminated source (Kim et al., 2004). High concentrations of low-chlorinated CBs, such as CB-52 may be from processes using chlorine oxidation; further, high-chlorinated CBs could be decayed to lighter ones by bacterial decomposition (Kim et al., 2004). Presence of mid-chlorinated CBs, such as Penta-CB (CB-101) and Hexa-CBs (CB-138 and CB-153) could be related to partitioning of these compounds to particulate organic matter. High-chlorinated PCBs, such as CB-180 possibly came from terrestrial pollution in the form of industrial sewage, or from marine traffic (Hong et al., 2005). Although no pattern in concentration $v s$. water depth was evident, deeper trench samples (C1-I-M-S078B10, TS03-S106GT02 (S), TS03S106GT02 (D), and TS03-S090LANDER11) exhibited higher $\Sigma_{7}$ PCBs (average $642.2 \mathrm{pg} / \mathrm{g}$ ) than C1-I-M-S015B02 (129 pg/g) values.

Toxic potency of PCBs was assessed by measuring Toxic Equivalence (TEQ) of twelve dioxin-like (dl-) CB congeners (CB-77, 81, 126, 169, 105, 114, 118, 123, 156, 157, 166, and 189) in all the sediment samples (normalised by multiplying their measured concentrations by the appropriate WHO-TEFs) (Table S-5). The respective TEQPCBs express these analyte concentrations as a single number, which is equivalent to toxicity derived exclusively from 2,3,7,8-TCDD. Mariana dl-PCB-TEQ concentrations ranged from 0.650 - $14.9 \mathrm{pg} / \mathrm{g}$ (Table S-6), with the highest TEQPCBs recorded at 9373D. Our results are higher than TEQPCBs values from past studies with sediments from shallow water depths, e.g., a semi-industrial area, Asaluyeh Harbor, Iran (0.001-3.4) (Arfaeinia et al., 2017); marine sediments from Mediterranean Sea, Catalonia, Spain
(0.03-24.8) (Eljarrat et al., 2001); or Han River, Korea (0.01180.626) (Kim et al., 2009). Surface marine sediments in shallow water are susceptible to organic pollution due to their proximity to industrial areas, as well as from atmospheric interactions. It is however, surprising to witness such contaminants have reached the deepest parts on Earth.

Unlike PCBs, concentrations of PBDEs were lower in the Trench samples. To maintain consistency (since PBDEs are presented as mixtures of congeners), and form a comparable dataset, a total of 8 PBDEs (BDE-28, 47, 99, 100, 153, highlighted in blue in Table S-3; BDE-54, 183, and 209 were not detected) were chosen (Zhang et al., 2016), which commonly occur in environmental samples. Their concentrations ranged from 36-289 pg/g. Mid-brominated congener BDE-153 was the most abundant, with concentrations ranging from $<$ LOD-166.0 pg/g d.w. (mean 43.3 pg/g). Penta-BDE mixture components BDE-47 and 99 possibly originated terrestrially from polyurethane foams (Yogui and Sericano, 2009), and were found at concentrations of <LOD $63.3 \mathrm{pg} / \mathrm{g}$ d.w. (mean $16.7 \mathrm{pg} / \mathrm{g}$ ) and <LOD $40.0 \mathrm{pg} / \mathrm{g}$ d.w. (mean $10.3 \mathrm{pg} / \mathrm{g}$ ) respectively. The PBDE congener distribution of Mariana sediments resembles those reported elsewhere in surface marine sediments from Europe (de Wit, 2002) and in Qingdao coastal sea sediments (Pan et al., 2007), China where BDEs 47, 99, and 153 were the most frequently reported congeners. Our results indicate that penta-BDEs could possibly be transported with water in the soluble and particle phases and degradation and fractionation of higher-brominated congeners (such as PBDE 209) may occur during long range transportation. $\sum_{8}$ PBDEs values (range $<$ LOD $0.289 \mathrm{ng} / \mathrm{g}$, mean $0.082 \mathrm{ng} / \mathrm{g}$ ) (Table S-3) for Mariana Trench sediments are lower than those in shallow water surface marine sediments recorded in past studies. Looking at the research carried in San Francisco Bay sediments, the $\sum_{8}$ PBDEs in each sample area (Suisun Bay, San Pablo Bay, Central Bay, and South Bay) range from 2.46-5.14 ng/g (Klosterhaus et al., 2012). In China, samples collected from offshore sediment of northern South China Sea, $\sum_{8}$ PBDEs is $0.93 \mathrm{ng} / \mathrm{g}$ and from East China Sea it is below $1 \mathrm{ng} / \mathrm{g}$ (Liu et al., 2015). The salient finding is that PBDEs were detected in the deepest Trench sediments with concentrations lower than, or nearing those of, coastal surface sediments adjacent to industrial areas. 


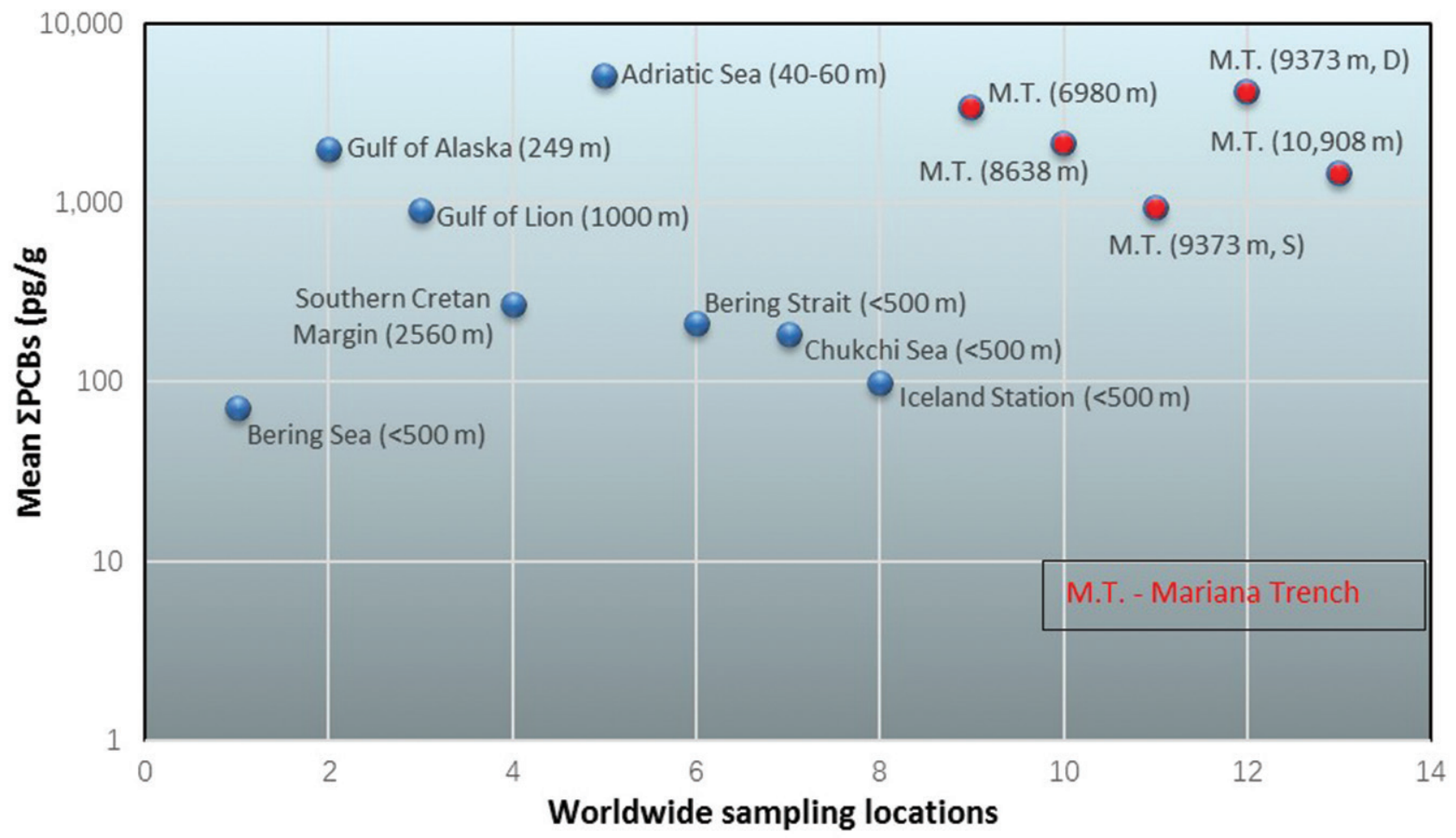

Figure 4 Comparison of $\sum$ PCBs concentrations in the Mariana Trench sediments with other worldwide marine surface water sediments. Figures in brackets indicate water depth.

We compared the level of $\Sigma \mathrm{PCB}$ concentrations in the Mariana Trench sediments to those reported in past studies at shallower depths (Fig. 4). The overall $\Sigma$ PCB values from our study (range: 931-4195 pg/g, mean 2424 pg/g) are overwhelmingly higher than those from shallow marine sediments studied in the past (Table S-7); and higher than the world baseline levels for $\Sigma$ PCBs arising from atmospheric transport found in clean coastal sediments, which is placed at $<1 \mathrm{ng} / \mathrm{g}$ d.w. (Phillips, 1986). However, the PCB concentrations in the sediments are markedly lower than those found in endemic amphipod fauna through bioaccumulation from 7000$10000 \mathrm{~m}$ in the Mariana (Jamieson et al., 2017), since these organisms have been known to rapidly locate and consume any particulate organic matter (POM) from surface-derived carrion falls. Further, pollutants can accumulate in the wax esters of capacious guts of larger amphipods, which are used as energy reserves in times of prolonged food deprivation (Lee et al., 2006).

Hadal communities, such as Hirondellidae tend to accumulate along the trench axis, where gravity driven down-slope transport of sediments results in a nutrient-rich environment (Ichino et al., 2015). However deep sea lysianassoid amphipods are also recorded from shallower trench depths of nutrient poor environments, thought to be advantageous due to limited competitive interactions (Blankenship and Levin, 2007). Post-mortal discharge of pollutants bioaccumulated by these endemic species and stored in the wax esters, or ingestion and faecal release may account for the high concentration of PCBs and PBDEs in the Mariana sediments. In addition, remote trenches encounter seafloor landslides or earthquakes. The funnel-like shape and high fluid dynamics within the Trench favour accumulation of pollutants along the trench axis (Turnewitsch et al., 2014), associated with these geotectonic events. However, apart from slightly higher organic carbon content in the Challenger Deep (0.3-0.4 \%) (Glud et al., 2013), hadal sediments are more depleted in total organic carbon (TOC), often reaching as low as $0.22 \%$ (Luo et al., 2017). Therefore, the dominance of organic matter-associated POPs in deep sea sediments over surface marine sediments seems paradoxical. We suspect that clay minerals may play a major role in the adsorption of contaminant particles in hadal sediments. Due to the lack of available studies, we conducted a preliminary mineralogical investigation of three sediment samples from deepest points by X-ray diffraction (XRD). Our results indicate clay assemblages (illite, nontronite, clinochlore, and gismondine) are abundant in the deepest sediments (Fig. S-2), with their total relative concentrations ranging from 51.8 to $86.5 \%$ in the three samples (Table S-8) A number of possible mechanisms of sorption of POPs with clay minerals are explained in previous studies (e.g., Li et al., 2015). For example, hydrogen bonding is demonstrated to bind polar groups of contaminants and basal oxygen atoms or adsorbed water of clay minerals (Wang et al., 2011). Binding of POPs in surface or interstitial layers of clays could act towards the agglomeration of pollutants in the hadal sediments. Further, long range transport of these pollutants could be linked to allogenic clays from terrestrial or shallow water origins.

The present discovery serves as evidence as to how far man-made pollutants have reached; and any such contamination will have ecological and toxic effects, long-term or ephemeral, depending on the scale of impact. Possibly, there no longer exists "pure land" that can completely be isolated from human activities in the Earth's ocean. High concentrations of pervasive pollutants in the trench sediments also imply that the Trench is a repository for POPs amplification, which occurs regardless of the source of these toxic anthropogenic pollutants. Certainly, high concentrations of POPs in the deepest ocean sediments are directly affecting hadal ecosystems, considering their persistent nature. The immediate challenge, therefore, is to assess the impact of anthropogenic pollutants reaching or residing in the deepest ocean. 
More detailed spatial and ecotoxicological studies on trench sediments will better our understanding of effects of POPs and other pervasive pollutants such as microplastics and litter in such environment.

Editor: Eric H. Oelkers

\section{Additional Information}

Supplementary Information accompanies this letter at http:// www.geochemicalperspectivesletters.org/article1814.

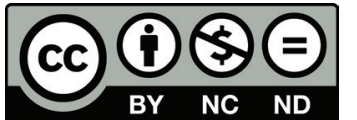

This work is distributed under the Creative Commons Attribution Non-Commercial No-Derivatives 4.0 License, which permits unrestricted distribution provided the original author and source are credited. The material may not be adapted (remixed, transformed or built upon) or used for commercial purposes without written permission from the author. Additional information is available at http://www.geochemicalperspectivesletters.org/ copyright-and-permissions

Cite this letter as: Dasgupta, S., Peng, X., Chen, S., Li, J., Du, M., Zhou, Y.-H., Zhong, G., Xu, H., Ta, K. (2018) Toxic anthropogenic pollutants reach the deepest ocean on Earth. Geochem. Persp. Let. 7, 22-26.

\section{References}

Arfaeinia, H., Asadgol, Z., Ahmadi, E., Seifi, M., Moradi, M., DOBARADARAN, S. (2017) Characteristics, distribution and sources of polychlorinated biphenyls (PCBs) in coastal sediments from the heavily industrialized area of Asalouyeh, Iran. Water Science and Technology $76,3340-3350$

BLANKENSHIP, L.E., LEVIN, L.A. (2007) Extreme food webs: foraging strategies and diets of scavenging amphipods from the ocean's deepest 5 $\mathrm{km}$. Limnology Oceanography 52, 1685-1697.

Combi, T., Miserocchi, S., Langone, L., Guerra, R. (2016) Polychlorinated biphenyls (PCBs) in sediments from the western Adriatic Sea Sources, historical trends and inventories. Science of the Total Environment 562, 580-587.

Dachs, J., Lohmann, R., Ockenden, W.A., Mejanelle, L., Eisenreich, S.J., JONES, K.C. (2002) Oceanic biogeochemical controls on global dynamics of persistent organic pollutants. Environmental Science and Technology 36, 4229-4237.

DE WIT, C.Y., (2002) An overview of brominated flame retardants in the envi ronment. Chemosphere 46, 583-624.

Eljarrat, E., CAIXACH, J., RiverA, J. (2001) Toxic potency of non- and monoortho PCBs, PCDDs, PCDFs, and PAHs in Northwest Mediterranean sediments (Catalonia, Spain). Environmental Science and Technology 35, 3589-3594.

Fujioka, K., Okino, K., Kanamatsu, T., Ohara, Y. (2002) Morphology and origin of the Challenger Deep in the Southern Mariana Trench. Geophysical Research Letters 29, doi: 10.1029/2001GL013595.

Glud, R.N., WenZhöfer, F., Middelboe, M., Oguri, K., Turnewitch, R. Canfield, D.E., Kitazato, H. (2013) High rates of microbial carbon turnover in sediments in the deepest oceanic trench on Earth. Nature Geoscience 6, 284-288.

Hong, S.H., YIM, U.H., SHIM, W.J., OH, J.R. (2005) Congener-specific survey for polychlorinated biphenyls in sediments of industrialized bays in Korea: regional characteristics and pollution sources. Environmental Science and Technology 39, 7380-7388.

ICHINo, M.C., Clark, M.R., Drazen, J.C., Jamieson, A., Jones, D.O.B., Martin, A.P., RowDEn, A.A., SHAnK, T.M., YANCEY, P.H., RuHL, H.A. (2015) The distribution of benthic biomass in hadal trenches: a modeling approach to investigate the effect of vertical and lateral organic matter transport to the seafloor. Deep-Sea Research I 100, 21-33.

Iwata, H., TANABE, S., Aramoto, M., SAKai, N., TATSUKaWA, R. (1994) Persistent organochlorine residues in sediments from the Chukchi Sea Bering Sea and Gulf of Alaska. Marine Pollution Bulletin 28, 746-753.
Jamieson, A.J., Malkocs, T., Piertney, S.B., Fuil, T., Zhang, Z. (2017) Bioaccumulation of persistent organic pollutants in the deepest ocean fauna. Nature Ecology and Evolution 1, 0051.

Kim, K.S., LeE, S.C., Kim, K.H., Shim, W.J., Hong, S.H., CHOI, K.H., YoON, J.H., KIM, J.G. (2009) Survey on organochlorine pesticides, $\mathrm{PCDD} / \mathrm{Fs}$, dioxin-like PCBs and HCB in sediments from the Han river, Korea. Chemosphere 75, 580-587.

Kim, M.K., Kim, S., Yun, S., Lee, M., ChO, B., PARK, J., Son, S, Kim, O. (2004) Comparison of seven indicator PCBs and three coplanar PCBs in beef, pork, and chicken fat. Chemosphere 54, 1533-1538.

Klosterhaus, S.L., Stapleton, H.M., La Guardia, M.J., Greig, D.J. (2012) Brominated and chlorinated flame retardants in San Francisco Bay sediments and wildlife. Environmental International 47, 56-65.

Kuku Ka, P., Audy, O., Kohoutek, J., Holt, E., KalábovÁ, T., Holoubek, I., KLÁNOVÁ, J. (2015) Source identification, spatio-temporal distribution and ecological risk of persistent organic pollutants in sediments from the upper Danube catchment. Chemosphere 138, 777-783.

Lee, R.F., Hagen, W., Kattner, G. (2006) Lipid storage in marine zooplankton. Marine Ecology Progress Series 307, 273-306.

Li, Z., Fitzgerald, N.M., Albert, Z., Schnabl, A., JiAng, W.-T. (2015) Contrasting mechanisms of metoprolol uptake on kaolinite and talc. Chemical Engineering Journal 272, 48-57.

LiU, L., Li, H., WANG, Z., LIU, R., ZHANG, Y., LIN, K. (2015) Insights into spatially and temporally co-occurring polybrominated diphenyl ethers in sediments of the East China Sea, Chemosphere 123, 55-63.

Lohmann, R., BreiviK, K., DACHS, J., Muir, D. (2007) Global fate of POPs: current and future research directions. Environmental Pollution 150, 150-165.

Luo, M., Gieskes, J., Chen, L., Shu, X., Chen, D. (2017) Provenances, distribution, and accumulation of organic matter in the southern Mariana Trench rim and slope: Implication of carbon cycle and burial in hadal trenches. Marine Geology 386, 98-106.

Ma, Y., Halsall, C.J., Crosse, J.D., Graf, C., CaI, M., He, J., GaO, G., JONES, K. (2015) Persistent organic pollutants in ocean sediments from the North Pacific to the Arctic Ocean. Journal of Geophysical Research: Oceans 120, 2723-2735.

Neira, C., Vales, M., Mendoza, G., Hoh, E., Levin, L.A. (2018) Polychlorinated biphenyls (PCBs) in recreational marina sediments of San Diego Bay, southern California. Marine Pollution Bulletin 126, 204-214.

PAN, J., YAnG, Y-L., XU, Q., Chen, D-Z., XI, D-L. (2007) PCBs, PCNs and PBDEs in sediments and mussels from Qingdao coastal sea in the frame of current circulations and influence of sewage sludge. Chemosphere 66, 1971-1982

PHILLIPS, D.J. H. (1986) Use of organisms to quantify PCBs in marine and estuarine environments. In: Waid, J.S. (Ed.) PCBs and the Environment Vol. II. CRC Press, Boca Raton, FL., 127-181.

RHIND, S.M. (2012) Anthropogenic pollutants- an insidious threat to animal health and productivity? Acta Veterinaria Scandinavica 54, S2.

Turnewitsch, R., Falahat, S., Stehlikova, J., Oguri, K., Glud, R.N., Middelboe, M., Kitazato, H., Wenzhoefer, F., Ando, K., Fujio, S. (2014) Recent sediment dynamics in hadal trenches: evidence for the influence of higher-frequency (tidal, near-inertial) fluid dynamics. Deep-Sea Research I Oceanographic Research Papers 90, 125-138.

WANG, C.J., LI, Z., JIANG, W.T. (2011) Adsorption of ciprofloxacin on 2:1 dioctahedral clay minerals. Applied Clay Science 53, 723-728.

WANIA, F., MACKAY, D. (1996) Tracking the distribution of persistent organic pollutants. Environmental Science and Technology 30, 390A-396A.

Yogui, G.T., Sericano, J.L. (2009) Polybrominated diphenyl ether flame retardants in the U.S. Marine environment: a review. Environment International 35, 655-666.

ZHANG, Y., WANG, W., SONG, J., ReN, Z., YUAN, H., YAN, H., ZHANG, J., PEI, Z., HE, Z. (2016) Environmental characteristics of polybrominated diphenyl ethers in marine system, with emphasis on marine organisms and sediments. BioMed Research International 2016, Article ID 1317232, 16 pp, doi: $10.1155 / 2016 / 1317232$ 